\title{
Modified Phase Contrast Microscopy and its Applications to the Observation of Marine Biological Objects
}

\author{
Ming Chang Shih \\ Institute of Opto-electronic Sciences, National Taiwan Ocean University. \\ Jiang-Shiou Hwang \\ Institute of Marine Biology, National Taiwan Ocean University.
}

Follow this and additional works at: https://jmstt.ntou.edu.tw/journal

Part of the Marine Biology Commons

\section{Recommended Citation}

Shih, Ming Chang and Hwang, Jiang-Shiou (2000) "Modified Phase Contrast Microscopy and its Applications to the Observation of Marine Biological Objects," Journal of Marine Science and Technology. Vol. 8: Iss. 1, Article 7. DOI: $10.51400 / 2709-6998.2454$

Available at: https://jmstt.ntou.edu.tw/journal/vol8/iss1/7

This Research Article is brought to you for free and open access by Journal of Marine Science and Technology. It has been accepted for inclusion in Journal of Marine Science and Technology by an authorized editor of Journal of Marine Science and Technology. 
Modified Phase Contrast Microscopy and its Applications to the Observation of Marine Biological Objects

Acknowledgements

The authors would like to thank professors J. R. Strickler, for his generous help to improve the optical system, and C.-t. Shih for his constructive comments on the manuscript. We acknowledge financial support by the Asia Pacific Research Foundation to M.C. Shih and National Science Council, NSC 89-2621-Z-019-006 to J.S. Hwang.

This research article is available in Journal of Marine Science and Technology: https://jmstt.ntou.edu.tw/journal/vol8/ 


\title{
MODIFIED PHASE CONTRAST MICROSCOPY AND ITS APPLICATIONS TO THE OBSERVATION OF MARINE BIOLOGICAL OBJECTS
}

\author{
Ming Chang Shih* and Jiang-Shiou Hwang**
}

Keywords: Artemia, Phase contrast microscopy, sea urchin, behavior.

\section{ABSTRACT}

We demonstrate the imaging technique for the study of marine micro-biota (e.g. size ranged from um to $\mathrm{cm}$ ) by modifying the Fourier optics with a near IR illuminating source to improve the contrast of the high spatial frequency images and to reveal the micro-structure of the observed biological object. We also present the application of this system to the study of swimming behavior of the Artemia in free space, and the detailed structure of the spines and podia of the sea urchin. The imaging system is consisted of a collimated laser beam, a high pass Fourier optics transform system, a near IR illumination source, and a CCD digital imaging recording system. From the images recorded, we are able to track the swimming trajectory and frame- by-frame motion of Artemia, and to observe how the spines and podia of the sea urchin react to the stimulation of the environment.

\section{INTRODUCTION}

Fourier optics microscopy is an effective approach to imaging the detail of fine structures of a low contrast object. Normally an amplitude object can be seen by its color, or tone, which causes dint of variation of light wave on the background. However, in certain cases, it is desirable to see the object to be transparent, that is, a phase object, providing no contrast with its background and altering only the phase of the light wave. Since visual observation cannot differentiate phase variation, therefore, biologists develop techniques for staining transparent objects in order to convert the phase object into amplitude object. This approach may, however,

Paper Received May 1, 2000. Author for Correspondence: J.-S. Hwang. *Institute of Opto-electronic Sciences, National Taiwan Ocean University. **Institute of Marine Biology, National Taiwan Ocean University. kill the living object studied. The phase contrast microscopy, which earned Zernike a Nobel prize in 1953, has found extensive applications to studies on minute organisms. Figure 1 is the basic set up of the phase-contrast imaging system. The phase front of an incident collimated plane wave is modulated by a phase object $\Phi(y, z)$,

$$
\begin{aligned}
& E_{i}(x, y, z, t)=E_{0}(x, y) \sin \left(k_{z} z-\omega . t\right) \\
& x, y, z \text { : coorninates } \\
& t: \text { time } \\
& E_{0}(x, y) \text { : amplitude } \\
& k_{z}: \text { wave vector } \\
& \begin{aligned}
& \omega: \text { frequency: } \\
& E_{D}(x, y, z, t)=E_{0}(x, y) \sin \left[k_{z} z-\omega . t\right. \\
&+\Phi(x, y, z)]^{(\text {diffracted wave from an object) }}
\end{aligned}
\end{aligned}
$$

In the case of small phase perturbation, the above equation can be approximated to,

$$
\begin{aligned}
& E_{D}=E_{0} \sin \left(k_{z} z-\omega \cdot t\right) \cos (\Phi) \\
& \quad+E_{0} \cos \left(k_{z} z-\omega \cdot t\right) \sin (\Phi) \\
& \text { if } \Phi<<1(\operatorname{small} \text { perturbation) } \\
& E_{D}=E_{0} \sin \left(k_{z} z-\omega \cdot t\right)+E_{0} \cos \left(k_{z} z-\omega \cdot t\right) . \Phi(x, y, z) \\
& \quad=E_{i}(x, y, z, t)+E_{d}(x, y, z)
\end{aligned}
$$

The first term is the incident plane wave, and the second term is the diffracted wave due to the phase object.

If we put a high pass spatial filter at the focal point to filter out the incident plane wave, the zero order part, then only the high spatial frequency part which is the diffracted wave can reach on the CCD image plane.

$$
E^{C C D}(x, y, z, t)=E_{0} \cos \left(k_{z} z-\omega . t\right) . \Phi(x, y, z)
$$

This is the so-called Schlieren method of dark background image, since without the object in place, $\Phi=0$, the image is complete dark in back ground. 


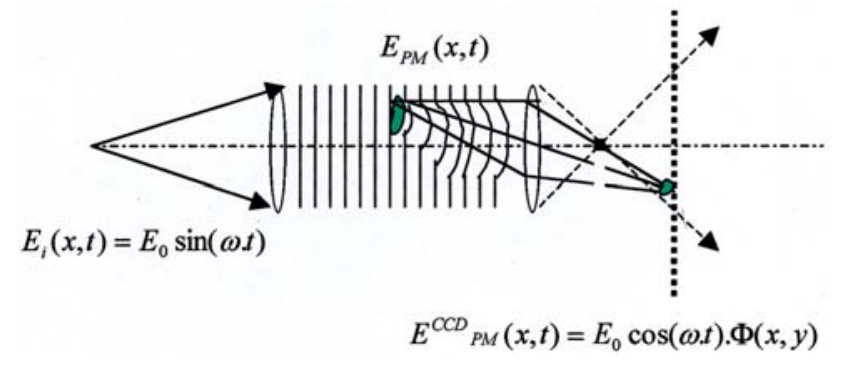

Fig. 1. The sketch of the phase-contrast system, shows that the Phase front of an incident collimated plan wave is modulated by a phase object $\Phi(y, z)$.

Figure 2 shows the difference between the conventional image and the image using phase contrast microscopy technique.

Since, marine micro-biota, particularly many zooplankters, are low contrast relative to their environment, and microscopically small, ranging in size from tens of micrometers to few millimeters, hence presenting a challenge to observe their swimming, feeding and other behaviors in free space. Strickler and Hwang (1999) developed a phase contrast imaging system by using a spatial filter to observe a phase object in long working distance [1-4], and showed phase contrast imaging technique to be an effective approach to study various behaviors of tiny, transparent marine objects. In addition, we modified phase contrast microscopy system with a near IR illumination source to compensate the zero order part of the diffracted wave and to improve the visual-resolution of the surface texture of the object.

\section{Experimental setup}

The schematics of the modified phase contrast microscopy system is shown in Figure 3, a collimated laser beam of plane-wave and uniform intensity incident on the objects So which is optically transparent. The diffracted light from the object then passes through a Fourier transform lens $L_{1}$, and is focused on a spatial filter which filter out the zero order part of the incident wave, then a lens $L_{2}$ is used to image the diffracted wave image on the CCD screen. The optical path is aligned with a collimated beam at $660 \mathrm{~nm}$ of a laser diode. When a clear phase contrast image is achieved, a near infrared illumination source $(780 \mathrm{~nm}-830 \mathrm{~nm})$ is used to compensate the zero order part of the diffracted wave, in such a way that the surface detailed structure can be seen clearly. The images of the objects in motion were recorded digitally by a $\mathrm{PC}$ based digital image acquisition system (Matrox II) at $100 \mathrm{~ms} /$ picture recording speed. It is easy to study the moving behavior of the
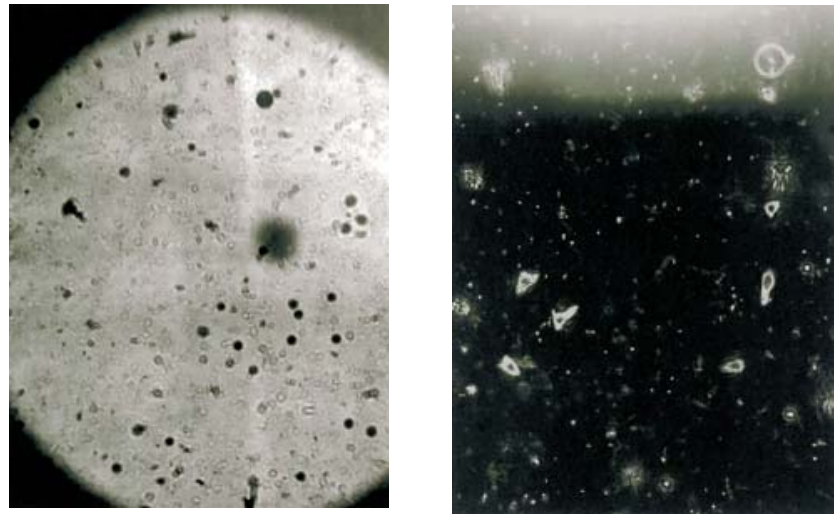

Fig. 2. Fourier transform image (right), and image taken by conventional photography (left), showing the high frequency filtering of the Fourier transform image.

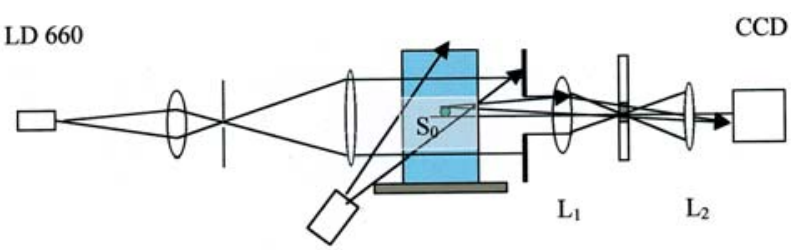

IR

Fig. 3. The schematics of the modified phase contrast microscopy system, a collimated laser beam of plane-wave and uniform intensity is illuminating the objects $S_{o}$ which is optically transparent. The diffracted light from the object passes through a Fourier transform lens $L_{1}$, and is then focused on the spatial filter. A high pass spatial filter and the lens $L_{2}$ is used to inversely Fourier transform the diffracted pattern of the observed object and to be imaged by the CCD. The IR illumination light source is used to improve the image quality.

marine object by reviewing the phase contrast images of the motions in real life.

Artemia, commonly known as the brine shrimp, belong to the phylum Arthropoda, class Crustacea. Their larvae are planktonic and form the primary food source for the early stages of many cultured fish and crustacean larvae [5-6]. Artemia are easily reared in the laboratory and have been a subject for intensive study on hatching, nutrition value, and response to aquatic environmental factors, such as temperature, light illumination, $\mathrm{pH}$ value and oxygen. However, reports of observations on free swimming that visualizes the detailed kinetic mechanism of the behavior in Artemia are lacking. The knowledge of the kinetic mechanism gained from observations on Artemia may apply to other marine micro-biota.

Approximately 12 hours after hatching, Artemia molt into the second larval stage and start filter feeding on microalgae, bacteria, and detritus. For the observa- 

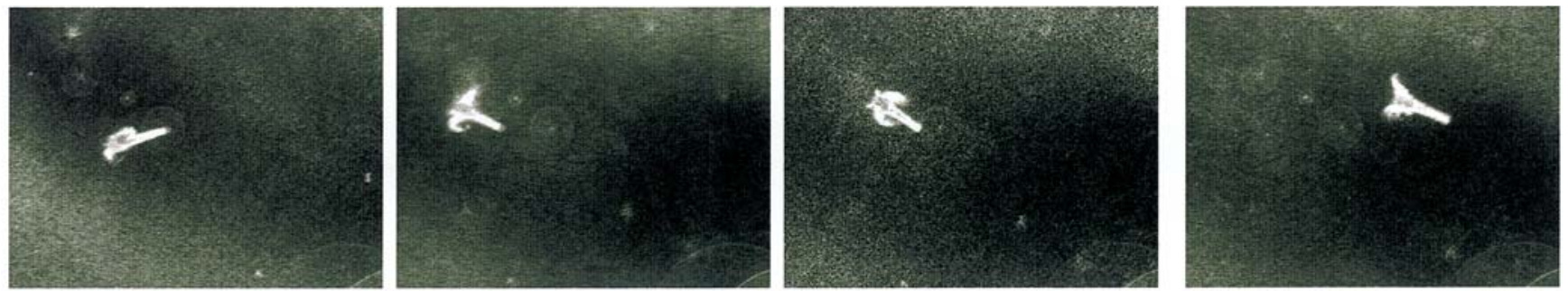

A

B
C

Fig. 4. A series of images (A, B, C, and D) of the continuous motion of the Artemia, showing the basic driving mechanism of forward motion being generated by the propelling of the second antennae.

tion of free swimming Artemia, we filter the larvae in a large number from the cysts in the hatching container, then put them into a glass research vessel of 12,5 , and $15 \mathrm{~cm}$ respectively in length, width, and height.

\section{Results \& Discussion}

\section{Study on swimming kinetics of Artemia}

Figure 4 shows a series of images of the swimming Artemia. These pictures show that the basic driving mechanism is generated to propel the powerful second antennae. Based on Artemia's swimming patterns, it is suggested that Artemia's posterior region of the body, may be responsible for the balance and orientation of the animal's body during swimming. It is also possible to measure the speed of Artemia's motion at different stage or under different conditions of its environment, such as variations in temperature. We found that the speed of Artemia is decreasing, in terms of its body length, as it is becoming matured. Approximately, the nauplii move as fast as 10 body lengths/sec but individuals reaching adulthood as slow as a few body lengths/ sec.

In our experiments of observing the response of Artemia motion to the change in water temperature, we used a high power IR lamb to heat the water locally. The temperature of the sea water can be heated to as high as $38^{\circ} \mathrm{C}$. The experiment shows that there is no significant changes in Artemia's swimming patterns. However, it is found that the speed of Artemia's motion increases with the increasing temperature. According to the physics of water, the higher the temperature, the smaller the viscosity of the sea water is, and therefore allowing Artemia to move faster. The effect of temperature on Artemia's motion behavior is probably due to the change in viscosity of the sea water or caused by Vant Hoff's law of Q10.
Observing the activity of the spines and podia of the sea urchin.

In sea urchin, their spines and podia are very sensitive to environmental stimulation, such as thermal stress, chemical stimulation, and mechanical vibration. The podium is a flexible, thin, movable tube-like structure, and is difficult to be observed by conventional photography. Figure 5 shows the image of spines and podia on the surface of a sea urchin. We can see clearly the fine surface structure of the spines and the podia in life. This modified Fourier transform microscopy system allows us to see small-sized e.g. micrometers to millimeters, to medium-sized e.g. centimeters, particles or organism.

\section{Conclusion}

We have demonstrated the modified phase contrast microscopy technique in the application of the study of marine object motion behavior. By using a near infrared illumination source to compensate the zero order of the diffracted wave, we are able to study the swimming behavior of Artemia and the spines and podia activity of sea urchin. Our results show that the long working distance of this modified microscopy technique is effective to the study of marine micro-biota, particularly observing their motion behaviors. In the future auto tracing system will be established to provide 3-D information of motion behaviors of zooplankton and other invertebrates. The 3D information is essential in understanding the behavior aspects of zooplanters and other invertebrates in small as well as large scales in their real life.

\section{ACKNOWLEDGEMENTS}

The authors would like to thank professors J. R. 

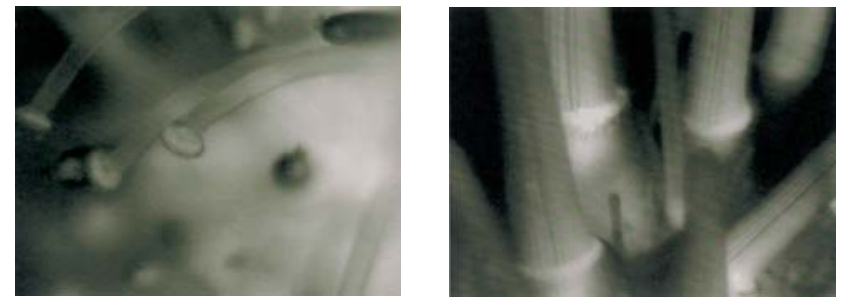

Fig. 5. The images of the podia (left) and the spines (right) on the surface of a life sea urchin., the surface fine structures of the podia and spines are clearly visible.

Strickler, for his generous help to improve the optical system, and C.-t. Shih for his constructive comments on the manuscript. We acknowledge financial support by the Asia Pacific Research Foundation to M.C. Shih and National Science Council, NSC 89-2621-Z-019-006 to J.S. Hwang.

\section{REFERENCES}

1. Trager G.C., Hwang J.-S., and Strickler J.R., Barnacle suspension-feeding in variable flow. Marine Biology. Vol. 105: 117-127 (1990).

2. Hwang J.-S., Turner J.T., Costello J.H., Coughlin D.J., and Strickler J. R., A cinematographic comparison of behavior by the calanoid copepod Centropages hamatus: Tethered versus free-swimming animals. Journal of Experimental Marine Biology and Ecology. Vol. 167: 277288 (1993).

3. Hwang J.-S., Costello J.H., and Strickler J.R., Copepod grazing in a turbulent flow: elevated foraging behavior and habituation of escape responses. Journal of Plankton Research. Vol. 16(5): 421-431 (1994).

4. Strickler J.R., and Hwang J.-S., Matched spatial filters in long working distance microscopy of phase objects. In
Cheng, P.-C., Hwang, P.-P., Wu, J.-L., Wong, G., Kim, H., (eds.) Focus on Multidimensional Microscopy. World Scientific Publishing Co., Singapore, pp. 217-239 (1999).

5. Bardach, J.E., Ryther, J.H. and McLarney, W.O., Aquaculture: the farming and husbandry of freshwater and marine organisms. Wiley Interscience, New York, pp. 868 (1972).

6. Browne, R.A., Sorgeloos, P., Trotman, C.N.A., Artemia Biology, CRC press, pp. 166 (1991).

\section{富氏顯微光學技術之改良及其應用 於海洋生物體之觀測}

$$
\text { 施明昌 }
$$

國立台灣海洋大學光電科學研究所

$$
\text { 黄 將 修 }
$$

國立台灣海洋大學海洋生物研究所

$$
\text { 摘 要 }
$$

我們改良富氏光學配合近紅外線照射以達成高 頻影像對比的效果以及展示觀察之微小生物體的微細 構造, 我們應用這個改良的光學系統去研究䇺年蝦在 三度空間之水體中的游泳行爲以及觀測活體海膽的刺 及足之顯微結構及運動過程, 本研究中的改良之影像 系統乃是由平行的雷射光束、富氏光學轉變系統還有 近紅外光源和 CCD 影像錄影系統組合而成。我們從得 到的影像中可以追蹤軖年蝦游泳的軌跡以及每一個螢 幕的慢動作過程我們也可以觀察到海膽的刺和足受環 境影響時的反應。 